\title{
UPCYCLING OBSOLETE MECHANICAL EQUIPMENT INTO INNOVATIVE LABORATORY TEST RIGS: A LOW-COST SOLUTION OR A SUSTAINABLE DESIGN APPROACH?
}

\author{
Rogkas, Nikolaos; \\ Tsolakis, Eustratios; \\ Kalligeros, Christos; \\ Vasileiou, Georgios; \\ Vakouftsis, Christos; \\ Kaisarlis, Georgios; \\ Markopoulos, Angelos P.; \\ Spitas, Vasilios \\ National Technical University of Athens, School of Mechanical Engineering
}

\begin{abstract}
Circular Economy (CE) and the potential of reusing and recycling the products after the end of their life, becomes imperative for environmental, economic and social reasons. Especially during the 4th Industrial Revolution that is taking place nowadays, an increasing number of out-of-date equipment has to be replaced, which constitutes a chance and necessity to be reused, through recycling, redesigning and remanufacturing. The paper presents proof-of-concept studies regarding upcycling of obsolete and outdated equipment into novel test rigs mainly addressing research activities. Three such case studies are presented, namely the upcycling of an injection moulding machine into a modular test bench for power hydraulic components, the upcycling of scrap components into a hybrid hydraulic/ ICE powertrain rig and the functional augmentation of a gear roll tester to accommodate single and double flank tests. Significant savings in cost, raw materials and time are demonstrated in all cases and adherence to the $\mathrm{CE}$ objectives are observed.
\end{abstract}

Keywords: Circular economy, Design for X (DfX), Upcycling, Sustainability, Retrofitting

Contact:

Rogkas, Nikolaos

National Technical University of Athens

Department of Mechanical Design and Automatic Control

Greece

nrogkas@mail.ntua.gr

Cite this article: Rogkas, N., Tsolakis, E., Kalligeros, C., Vasileiou, G., Vakouftsis, C., Kaisarlis, G., Markopoulos, A. P., Spitas, V. (2021) 'Upcycling Obsolete Mechanical Equipment into Innovative Laboratory Test Rigs: A Low-Cost Solution or a Sustainable Design Approach?', in Proceedings of the International Conference on Engineering Design (ICED21), Gothenburg, Sweden, 16-20 August 2021. DOI:10.1017/pds.2021.592 


\section{INTRODUCTION}

Environmental degradation and climate change are globally well-acknowledged facts that are in the focus of the political, financial, and scientific community. Nowadays the deterioration of the earth's ecosystem includes the unprecedented depletion of natural resources, the over-commitment of available lands for waste disposal (landfilling) and the pollution of air and water due to traditional energy production methods or human-related activity (Geissdoerfer et al., 2017). Accordingly, governments and organisations are establishing strict and dynamic regulations to attain sustained economic growth, environmental protection, and societal wellbeing.

Industrial engineering and product design are fundamentally related to the imperative sustainability requirements since almost all the products consumed by people are outputs of the product development process. For instance, it is estimated that carbon dioxide emissions of the US industrial sector will be increased to $1667 \times 10^{7}$ by 2030 from $1235 \times 10^{6}$ back in 2007 (Ramani et al., 2010). Aiming to address the sustainability issues on product development process, novel design approaches are being studied in numerous recent publications (Chouinard et al., 2019; Kutz, 2007; De los Rios and Charnley, 2017). In that context, the concept of circular economy (CE) has emerged and recently gained increased attention. $\mathrm{CE}$ denotes the transformation of the traditional linear production process, based on the "take-makedispose" plan, into an interacted closed loop. In the former, a product is thrown away after use, whereas in the latter the reuse or the recycling of the product after its end of life (EOL) is efficiently enabled, leading to significant reduction of the consumed energy and physical resources. In brief, CE is one that is restorative and regenerative by design and aims to keep products, components, and materials at their highest utility and value at all times (EMF, 2015). Intense effort towards the standardization in the field of CE is conducted by the ISO/TC 323 Technical Committee, established in 2019. Bringing together experts from 75 countries, the ISO/TC 323 has been tasked with developing standards that will provide consistent and unambiguous tools and guidance for the implementation of CE.

Engineering design activities embedded in the CE philosophy are categorized from various perspectives in relevant publications (Jawahir and Bradley, 2016; Mihelcic et al., 2003; Reh, 2013; Sauerwein et al., 2019; Tolio et al., 2017). This diverse categorization often yields controversy and leads to blurry spots on the understanding of the CE design-related core concepts. Pigosso and McAloone (2017), presented a brief overview on the design topics in the context of $\mathrm{CE}$, including design processes, design organisation and management, design research application and case studies, products services and system design, design methods and tools and design for X. Despite the differences between the categories they all share the main goal of 'circular design'. Most widely known as 'the power of inner circle' (EMF, 2015), the goal is to create added value within the design process from a perspective which includes the use of raw materials, manufacturing, labour and consumed energy.

In order to assess the contribution of CE-related principles on the design process from a technical perspective and to interpret the potential strategies, the 3Rs (reduce, reuse, recycle) or 6Rs (augmented 3Rs with the addition of remanufacture, redesign and recover) models are often incorporated (Jawahir and Bradley, 2016; Kutz, 2007). Each of the above 'R-terms' have their own significance and it is necessary to properly understand the differences between them, e.g. 'recycling' involves a complete loss of shape and is considered as a waste treatment whereas 'reuse' implies a totally different strategy. In the scope of this research work the distinction established by Ali et al. (2019), between recycling and reusing is further elaborated by the term 'upcycling', which is hence adopted. From the materials viewpoint, they consider the impact of reuse practices over recycling on the worldwide steel production. Furthermore, they emphasise the fact that approximately 35\% of the world's steel is currently produced from scrap sources but the smelting processes of scrap steel during the production phase require about $1 / 3$ of the equivalent energy for making steel from virgin ore. Since smelting processes during steel recycling are expensive and energy-consuming, the direct reuse of steel materials without smelting could potentially outdate recycling.

Furthermore, in order to attain a sustainable design with positive energy impact, 6Rs principles are incorporated in a broad range of engineering design applications. For instance, Bendikiene et al. (2019) investigated the use of alloyed steels and cast irons as well as scraps of worn-out grinding wheels, hard metal inserts and other debris of industrial waste from high-speed tool steels for the manufacturing of wear-resistant coatings. In the work of Ali et al. (2019) the non-hazardous automobile by-products and the building industry are connected through the creation of a bio-inspired building 
facade system (Voronoi) from galvanized sheet metal waste from the automotive industry. Nilakantan and Nutt (2015) investigated the reuse and upcycling of aerospace prepreg scrap and waste.

Currently, the use of the term "upcycling" largely concerns the necessity to meet basic human needs to make objects of beauty via crafts (Bridgens et al., 2018). However, in the field of engineering design, upcycling means the reuse of discarded/ obsolete material in a way that yields a new product of higher quality or value than the original. This study, which follows the context of the work conducted by Wang et al. (2018) regarding the maximisation of the value of retired mechanical products, presents the upcycling process of obsolete mechanical equipment into novel experimental rigs for laboratory research activities of the Machine Design Laboratory of the National Technical University of Athens (MD Lab). Through this process, which includes a rigorous detailed design stage, old mechanical structures are combined with modern electrical/ electronic components and mechanical subassemblies to produce high added-value equipment. The approach is particularly challenging since laboratory test rigs require high levels of accuracy in terms of manufacturing, structural integrity, stability over time, measurement noise cancellation, and data acquisition. Nevertheless, this is made possible since the majority of structural parts found in old machinery usually surpass their modern counterparts in terms of rigidity, stiffness and geometric accuracy due to their high manufacturing quality. Another critical parameter for designing modern test rigs is to incorporate polyfunctionality i.e. ability to carry out a number of different tests that comply with different standards relative to each other. For instance, the assessment of the tribological properties of materials used in clutch and brake discs involves the conduction of pin-on-disk, disk-on-disk, block-on-ring etc. tests using a multitude of dedicated test rigs, therefore the advantage offered by the use of a single polyfunctional test rig to conduct all of the above tests is evident.

At present, the majority of the MD Lab test rigs have been developed in-house through upcycling, utilizing the CAD-CAE systems and the fully functional mechanical workshop of the lab. This experience has led to the development of a rigorous upcycling process, which comprises distinct stages aiming to maximise the benefit of using obsolete mechanical equipment for the successful design outcome through their combination with modern equipment. The internal procedures followed are demonstrated in this study with three representative case-studies. Since no standard methodology is yet widely accepted by the design society to address the issue of 'Design for Upcycling', the authors believe that the presented case studies contribute towards this goal concerning design and manufacture of test rigs, while embodying CE principles further into the design society itself.

\section{SUSTAINABLE \& LOW-COST UPCYCLING OF LABORATORY TEST RIGS}

One of the major issues in university laboratories is that of handling obsolete experimental/ testing equipment due to the costs involved, the space limitations, new functions that become necessary and familiarisation of the personnel operating the testing machines. This need is ever increasing and becomes much more frequent due to the rapid technological developments both in terms of needs/functions and of available testing machines. The case is usually about upgrading the software and electronics, which is typical of retrofitting, however the incorporation of multiple functions in a testing machine is also required. Therefore, the classical concepts of retrofitting and recycling of obsolete laboratory facilities in the context of CE is gradually transformed into upcycling of the facilities in question.

One of the important prerequisites for this upcycling is the ability to define the design problem properly (i.e. which functions, to which extend, how, how-much, when etc.) and to carry it out using in-house design and simulation tools and experience. This is usually the case in university laboratories, where teams possessing experience and software design tools exist, although it is a task that could be outsourced as well. In order for the aforementioned design work to fall within the context of upcycling, the following concerns should be addressed:

a. Reuse of a considerable portion of the existing obsolete equipment (i.e. more than $70 \%$ volume or weight in one or more new pieces of equipment)

b. Preserve a significant part of the functionality of the obsolete machinery (i.e. increased stiffness/ rigidity, manufacturing accuracy, monolithic design, passing the 'test of time')

c. Combine functions of the obsolete equipment with new functions of modern equipment and add-ons (i.e. data acquisition, drives, electronics)

Based on the experience gained through many such projects completed in MD Lab, the general rules presented above evolved to a standardized procedure. When mechanical equipment is categorized as 
obsolete, its distinct parts and subassemblies are evaluated and categorized based on their capability to be recycled or upcycled. The decision process for this categorization includes the assessment of the following indicators (metrics):

i. The component value (Euros/piece); if the market value of the component is below a threshold (i.e. 2 Euros/piece), the component is not stored for upcycling.

ii. Present value comparted to the expected value in the refurbished condition (\%);

iii. Relative cost of incorporated refurbished equipment to the cost of using new equipment (\%).

iv. Support from manufacturers through expected life cycle of refurbished equipment (yes/no).

v. Reliability (i.e. operation hours / number of cycles / probability of failure).

The parts found suitable for upcycling are stocked and further classified based on their functionality (structural components, electronic equipment, hydraulic systems etc.). The specifications of each part, including catalogues and CAD representations, are stored in a dedicated database. When there is a need for a new test rig and the technical specifications are set, the design team has to make a decision on whether it will be purchased from the market or designed and manufactured through the upcycling process presented above. The decision is made after the team assesses which parts can be reused as they are, redesigned and remanufactured from the stock and performs the cost analysis for the manufacturing of the new test rig. If the total cost is expected to be more than 3 times lower than the corresponding market value and at least $70 \%$ of the weight or the volume of the test rig consists of reused parts from the stock, the upcycling process is approved and the detailed design process gets underway. The appropriate analytical calculations and finite element analysis are performed to determine the properties of the new test rig and ensure that all specifications are met. The final result is a new, tailor-made and low-cost experimental test rig constructed following the $\mathrm{CE}$ and 6Rs principles.

In order to better illustrate the procedure presented above three design projects that took place in MD Lab are presented in the form of case studies. The first is the redesign of a hydraulic test bench, where emphasis was put on reusing and redesigning mechanical parts of obsolete mechanical equipment. The second is the design and manufacturing of a novel hybrid powertrain test rig where the major concern was to use as many scrap components as possible through remanufacturing. The third is the case of an obsolete gear tester for double-flank measurements, where the augmented functionality (ability to carry out also single-flank gear measurements) was the most important design objective. The proposed case studies share the aspect of the structural foundation/ chassis of the rig; i.e. metallic structural components of outdated machines are used for that purpose, pursuing the sustainability challenges described in section 1 .

\subsection{First case study: Upcycling of an old injection machine into a modular test bench for power hydraulic components}

In the field of power hydraulics, testing of components' performance is associated with a variety of measurements depending on the part examined. This could be hydraulic power-loss measurements of a pump, measurement of the response time of valve opening, burst pressure assessment of a pipeline, the derivation of the dynamical characteristics of a circuit, etc. The aim is to design a single polyfunctional test bench able to perform all of the above tests. However, in such a design attempt, the need for modularity contradicts the need for stiffness and dimensional stability under operation. To that scope, an elaborate evaluation of the available frames from the stock led to the selection of an old FROMAG injection moulding machine (nearly fifty years of age), which was upcycled into such a test bench (Figure 2). Due to the inherent high pressure of such systems, operation and testing are associated with high loads (in the range of up to $100 \mathrm{kN}$ ) which the reaction frame has to withstand. The rigidity of the frame were investigated through finite element analysis (FEA) and even though the first eigenfrequency was considerably high, around $40 \mathrm{~Hz}$ as shown in Figure 3, a first eigenfrequancy in the order of $100 \mathrm{~Hz}$ was needed to sustain the dynamic excitations foreseen for the bench. Through a redesign process, additional steel reinforcements were fitted to the frame (Figure 2) to increase its rigidity and as a result its first eigenfrequency reached the desired levels as shown in Figure 3. Apart from its rigidity, the aforementioned frame was selected on the basis that it provided mounting capability for various components, without compromising rigidity, enhancing the modularity of the new test rig. Another positive outcome of this work was the reuse of the expensive parts (i.e. hydraulic pumps) from the stock. Particularly the reuse of the high pressure actuator accompanied by maintenance of seals and other consumables have saved a considerable amount of raw material required for their reconstruction as shown below. The estimated initial weight of the machine was 
approximately 1.5 metric tons, including some mounting plates for its hydraulic actuators. More than $80 \%$ of the steel frame was utilised. Figure 1 depicts the initial state of the old injection machine, having removed the actuators. The final design is given in Figure 4.
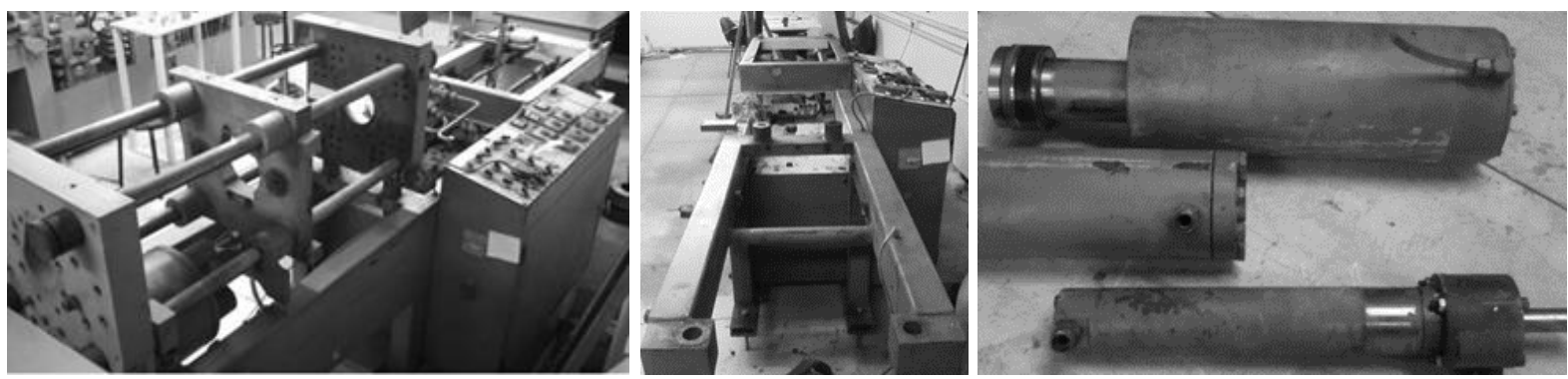

Figure 1. Chassis of the outdated FROMAG injection moulding machine (left and center) and hydraulic actuators of the old machines which were recovered (right)
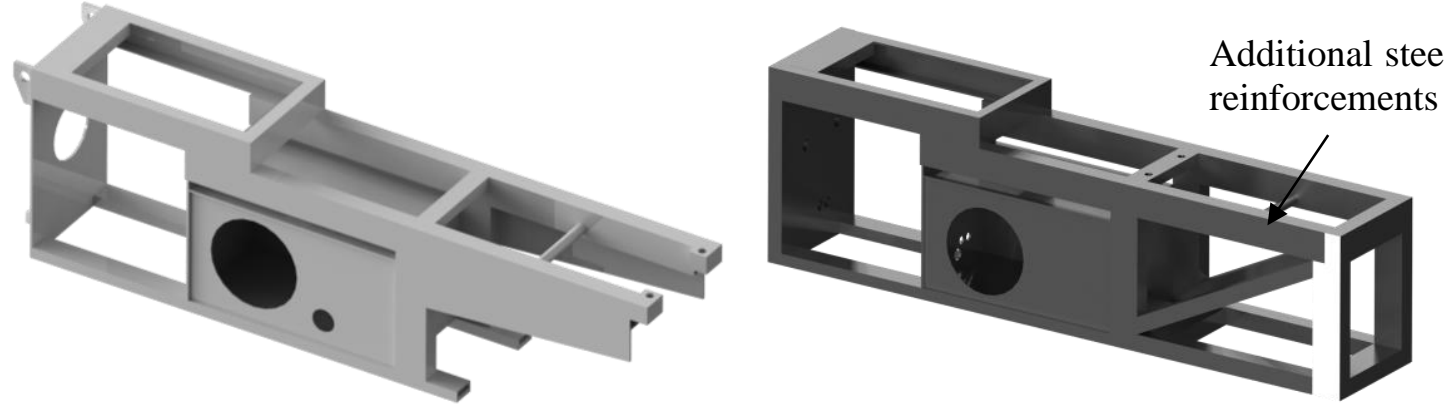

Figure 2. CAD representation of the chassis upgrade
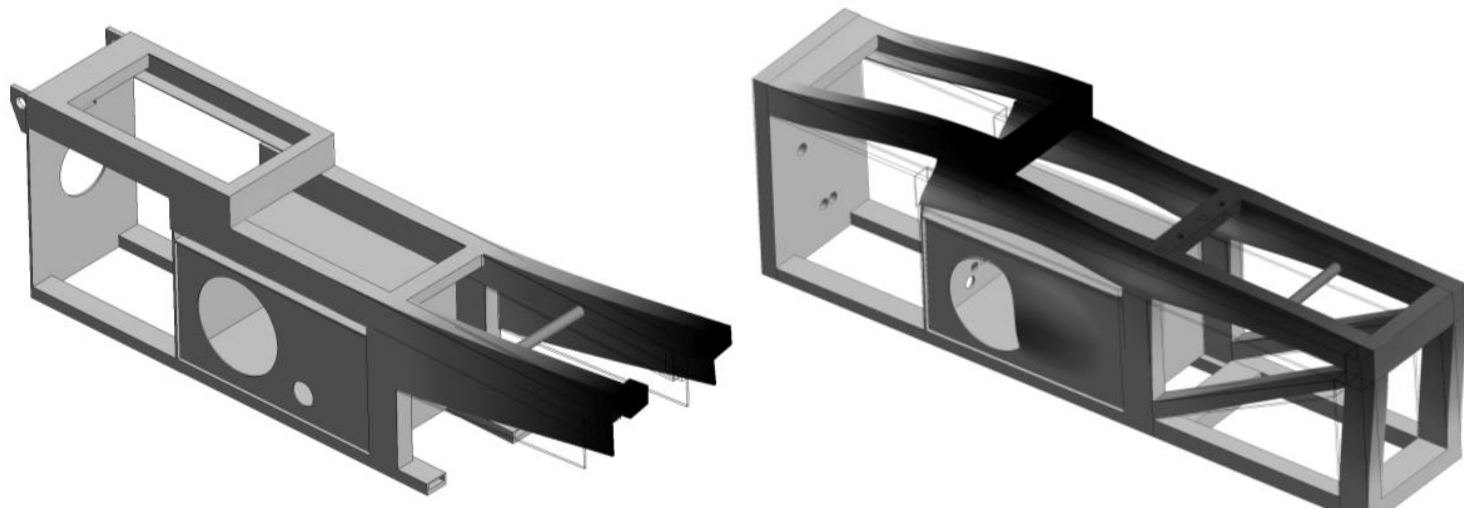

Figure 3. Modal analysis using the finite element software ANSYS. Left: recovered frame, first frame Eigenfrequency: $41 \mathrm{~Hz}$, Right: redesigned frame, first frame Eigenfrequency:

$101 \mathrm{~Hz}$ 


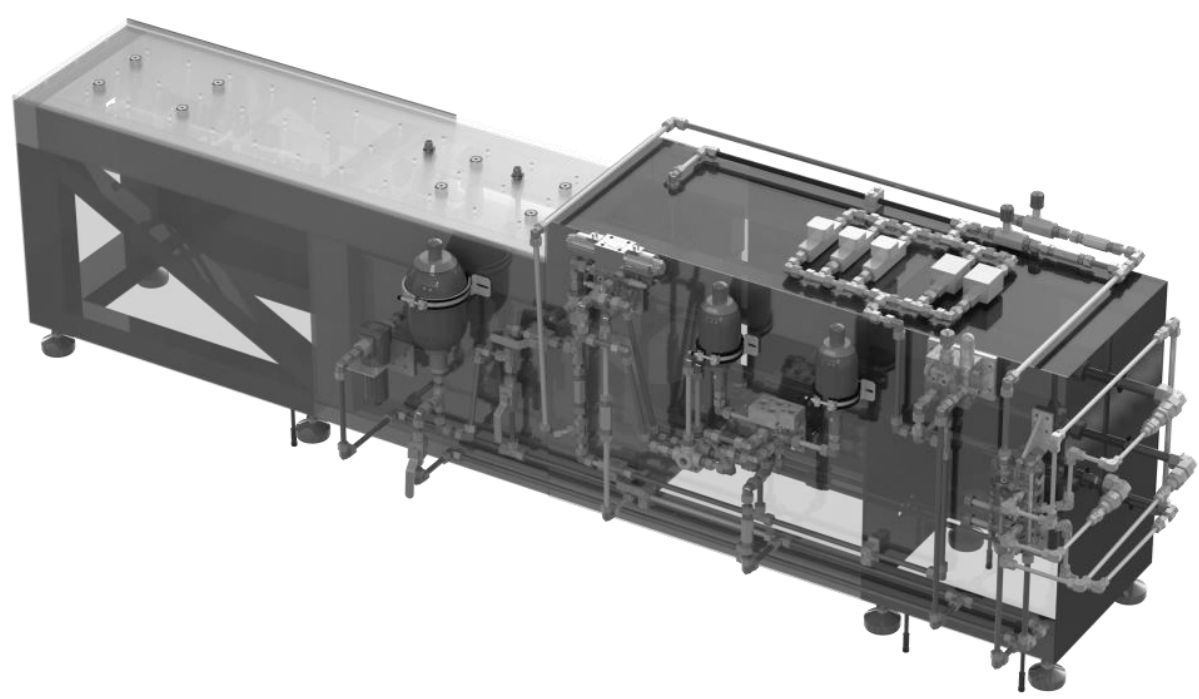

Figure 4. Design of the upcycled test bench

The case study that was presented above is a representative demonstration of the 6Rs protocols implemented by MD-Lab to incorporate the CE philosophy into the design process as showcased in Fig. 5. The resused, redesigned and remanufactured components of the new experimental rig surpassed the $90 \%$ of the rig both in terms of weight and volume. In addition, the cost saving that was achieved was remarkable. Indicatively, solely the reuse of the high pressure actuator is estimated to have saved around $400 \mathrm{~kg}$ of raw material required for their reconstruction. Even higher were the savings in terms of energy and manufacturing costs (honing, chrome-plating of cylinders, etc.) surpassing the amount of 100kEuro. The detailed information regarding the cost savings and the efficiency of the proposed design procedure in the context of $\mathrm{CE}$ is given in Table $1 \& 2$.

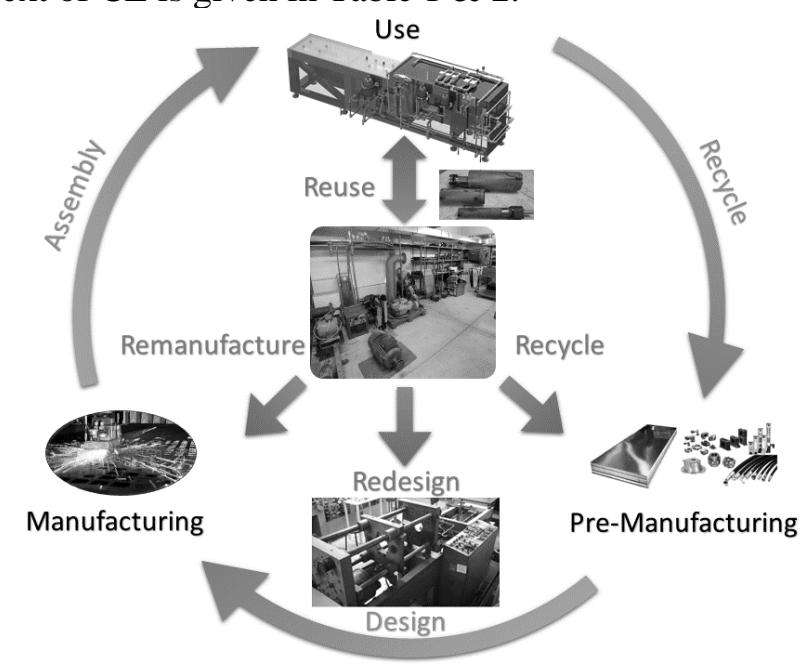

Figure 5.6Rs principles in the design of a hydraulic test bench of MD Lab, NTUA

\subsection{Second case study: Design of a Hybrid hydraulic/ ICE powertrain test rig from stock repository}

An alternative to the hybrid ICE-EM powertrains are the ICE-hydraulic layouts. Hydraulic pumps and motors comprise increased power to weight ratio, thus the investigation of their incorporation in vehicles is intriguing and is also supported by the potential replacement of gearbox and its components. In their most simple form, they consist of a hydraulic pump of fixed or variable flow rate, pipes, accumulators in order to provide quick response time at extreme driving conditions, and hydraulic motors on the driving wheels implementing open or limited slip differential operation. Regardless of their potential, research on hybrid hydraulic powertrains remains limited compared to the hybrid electric ones and this renders experimental approaches as necessary tools to investigate their potential and support the development and industrial exploration stage. 
To that scope, the development of a test rig for validating the above idea was performed based on the hydraulic circuit diagram presented in Figure 6. The design of the structural components and the selection of the hydraulic systems was conducted on the principle of the upcycling process. All the structural parts of the new test rig were remanufactured from scrap and components that were present in the lab from dismantling of outdated machinery (including the injection moulding machine of 2.1), stored in the stock. In addition, various hydraulic valves, accumulators, internal combustion engine and other miscellaneous components, were integrated on the manufactured steel frame to comprise the required test rig. In that way, a novel experimental rig for investigating the implementation of the hydraulic powertrain for vehicles was manufactured using $100 \%$ resused, recycled or remanufactured components.
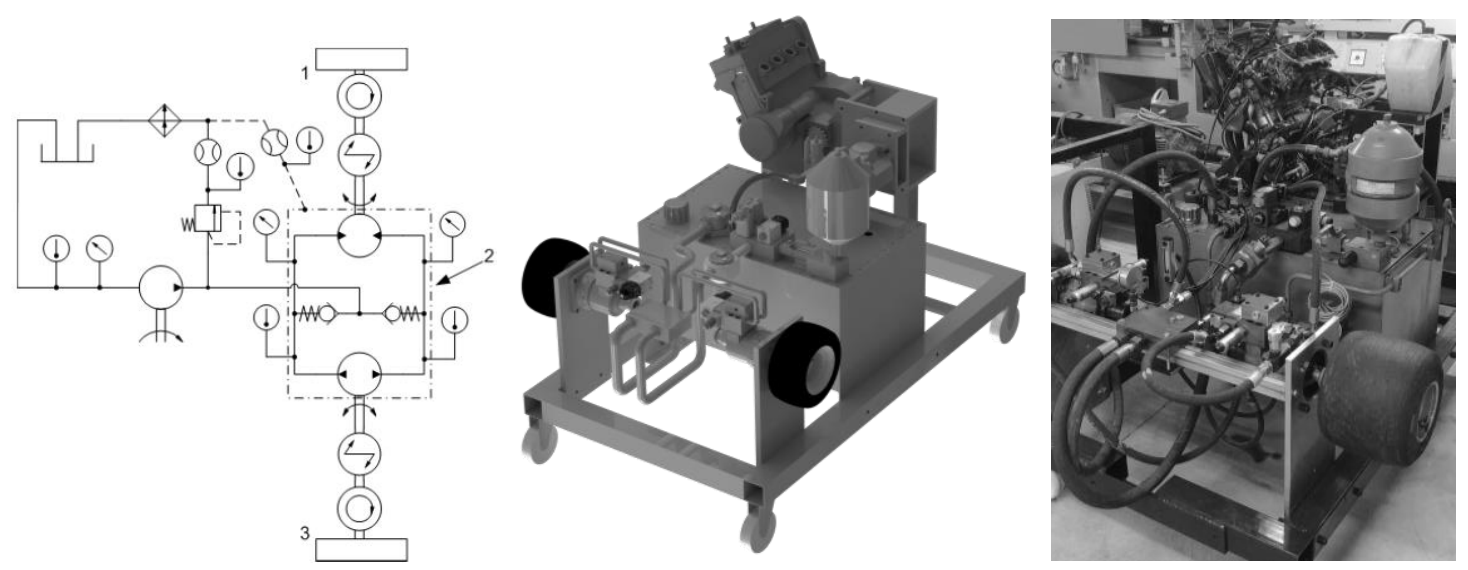

Figure 7. Hybrid ICE-Hydraulic powertrain. Left: Hydraulic circuit, Middle: CAD representation, Right: Manufactured test rig

\subsection{Third case study: Functional augmentation of an outdated gear tester}

Functional testing of gears in the form of single flank and double flank testing is one of the most commonly used inspection methods regarding gear accuracy. Even though double flank testers are usually preferred by industries and laboratories due to the lower cost of the equipment and the capability to provide information about the deviations in the tooth thickness of the testing gear, single flank testing is regarded by many as more useful since it gives information about the geometry of the testing gear and the profile deviations of its flanks. A universal polyfunctional measuring machine that performs both single and double flank roll tests can combine their measurements in order to minimise the uncertainty of the accuracy class characterization of the testing gear.

MD Lab has owned a Goulder Mikron gear double flank roll testing device since the early 80s. Despite its age, the chassis of the device was in a very good shape and it required only minor maintenance work. In the context of $\mathrm{CE}$ and $6 \mathrm{R}$ design protocols the double flank tester was used as the frame of the new universal testing machine. The main focus of the upcycling process was to replace all of the obsolete systems of the device with state-of-the-art equipment and to make the necessary adjustments to enable the performing of single flank roll measurements.

Originally the rotation of the gear wheels was performed manually, while the axial displacement of the gear centers was measured via a mechanical device with a stylus recording the results to a millimeter paper. In order to accurately control the angular velocity of the gear wheels, a new custommade main spindle has been installed in the device driven by an electrical motor. Furthermore, the old rotary and displacement transducers were replaced by state-of-the-art rotary and linear encoders respectively. Indicatively, the accuracy attainable by the original measuring system was in the order of $20 \mu \mathrm{m}$, while the new linear encoder has a rated accuracy of $0.1 \mu \mathrm{m}$ over the $4 \mathrm{~mm}$ gauge length. In addition, it enables the direct connection with a computer to post-process and store the measurements for every test gear. Also, two rotary encoders were installed to monitor the angular position of the gears in mesh in real time. The first encoder is mounted on the chassis, while the second is assembled on a special mount produced by additive manufacturing as shown in Figure 8. During the upcycling of the test rig it was pursued to reuse the majority of the original systems. The upgraded device equipped with both rotary encoders is now able to perform single flank measurements (not foreseen in its original version) along with double flank measurements (foreseen in the original version) according to existing standards, thus achieving functional augmentation. Modern machines which are able to perform single-flank and double-flank gear roll testing are not available in the market and the 
procurement of two such machines to achieve the same functionality would require a budget exceeding 200kEuro.

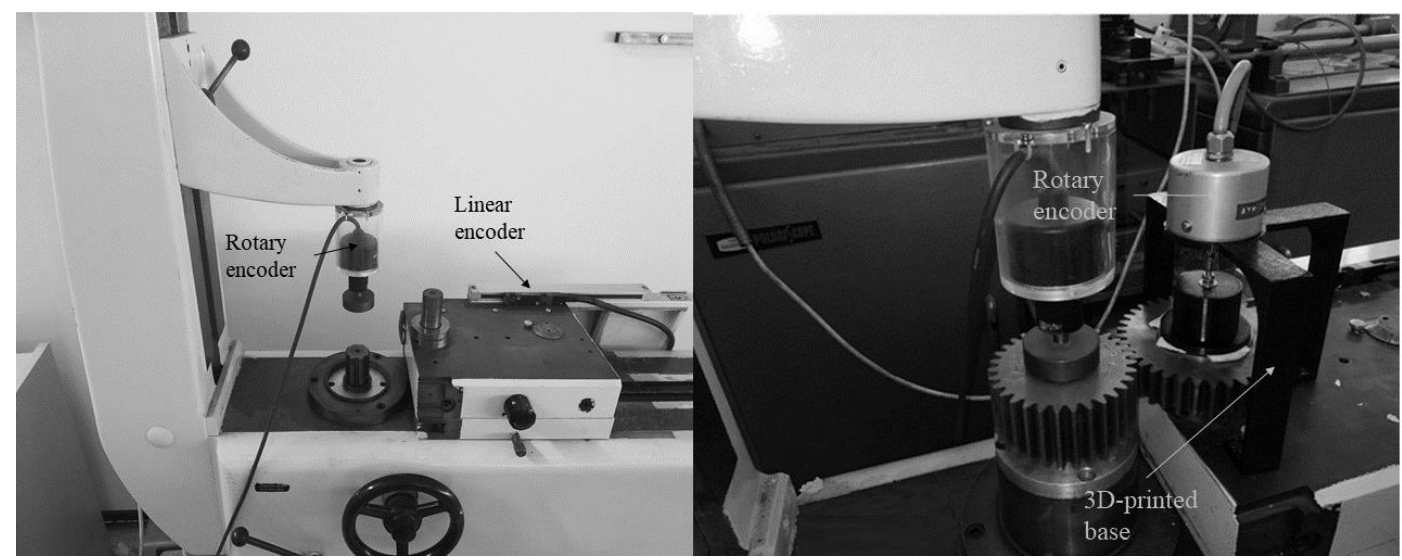

Figure 8. The upcycled Goulder Mikron gear roll tester. Left: An overview of the rig, Right: The modular 3D-printed base for mounting an extra rotary encoder

The cost details of the above case studies are presented in Table 1 and the portion of test rigs weight and volume made by $6 \mathrm{R}$ activities is demonstrated in Table 2 .

Table 1. Cost analysis and savings

\begin{tabular}{llll} 
Cost type (Euro) & Case study 1 & Case study 2 & Case study 3 \\
Market equivalent (indicatively*) & 125,000 & 38,000 & 200,000 \\
\hline \hline 6R Activities & 10,000 & 5,000 & 10,000 \\
Additional parts & 10,000 & 0 & 25,000 \\
Labour & 5,000 & 5,000 & 5,000 \\
Sum & 25,000 & 10,000 & 40,000 \\
\hline \hline Total save & 100,000 & 28,000 & 169,000 \\
\hline Percentage save & $80.0 \%$ & $73.7 \%$ & $84.5 \%$ \\
* Market values were provided after direct communication with manufacturers &
\end{tabular}

Table 2. Portion of test rigs weight and volume made by $6 R$ activities

\begin{tabular}{lllllll} 
6R Activities & \multicolumn{2}{l}{ Case study 1} & \multicolumn{2}{c}{ Case study 2} & Case study 3 \\
& Weight & Volume & Weight & Volume & Weight & Volume \\
& $(\%)$ & $(\%)$ & $(\%)$ & $(\%)$ & $(\%)$ & $(\%)$ \\
Reuse & 30 & 30 & 60 & 70 & 90 & 90 \\
Redesign & 65 & 55 & 0 & 0 & 0 & 0 \\
Remanufacture & 2 & 5 & 40 & 30 & 0 & 0 \\
Total & 97 & 90 & 100 & 100 & 90 & 90
\end{tabular}

\section{DISCUSSION AND CONCLUSIONS}

This study presents the rigorous upcycling process of obsolete mechanical equipment into novel test rigs developed in MD Lab. The parts and subassemblies of the obsolete equipment are assessed on their capability to be upcycled based on specific metrics. Those intended for upcycling are stored in a stock repository and their specifications are imported to a dedicated database. When a new test rig is required for the lab activities, a preliminary design process is performed to decide whether the test rig should be purchased from the market or designed and manufactured utilizing the components stored at the stock repository. The decision is based on the achieved levels of cost savings and reused parts.

The presented case studies illustrate that the demonstrated upcycling process of parts of out-of-date machines in the frame of CE is feasible and efficient. In all cases a reusage percentage of over $90 \%$ was achieved, while the total cost savings varies between $75-85 \%$. Based on the positive results of this introductory analysis, further advances in this field may offer even more promising results. One of the most critical steps of the upcycling procedure presented above is the determination of the indicators 
and their threshold values indicating which components of the obsolete equipment will be stored in the repository and under which conditions the upcycling for a new test rig is beneficiary. Thus, a new methodology can be developed to determine these indicators depending on the special needs of every laboratory or industry. The indicator values could be determined based on distinctive data of each lab or industry such as test rigs need (i.e. pieces/year), available repository volume, suppliers' network, etc. In addition, the efficiency of the upcycling process could be estimated by a more sophisticated objective function that takes into account not only the weight and volume percentages but also cost, availability and functionality aspects.

Within the modern industrial environment, in the concept of Industry 4.0, and considering that it is a dynamic and constantly evolving field, the need of versatility is interwoven with the meaning of competitiveness since technology is evolving exponentially with time. Additionally, there is a constant trend to incorporate many features into a single set-up, aiming to a more complete and spherical approach with reduced costs at the same time. For example, since a significant number of measurements are needed for every single test, it is scientifically proper and preferable that all measurements are simultaneously taken. This requires tailor-made/ hybrid test rigs, with many embodied sub-systems, while these rigs can be easily updated without the necessity of long period for calibration and tests. The utilization of already employed equipment consists a feasible solution, since any previously acquired knowledge can be used cumulatively.

Finally, a key-aspect of CE is the financial benefit of reusing the equipment. The 4th Industrial Revolution results in a huge amount of out-of-date equipment, while at the same time, the gap between the advanced and the developing countries is still growing, not only in terms of production capabilities, but in technological education as well. This becomes even more pronounced in view of the expected COVID-19 pandemic side-effects in global finance and economics. Hence, the volume of retired machinery constitutes an almost unlimited repository of means that could bridge the aforementioned gap. The upcycling, redesigning and reusing of said machine elements can provide equipment of low cost, which may promote the research where the financial resources are limited. In conclusion, the applicability of CE has not only environmental benefits, but financial and societal benefits as well.

\section{REFERENCES}

Ali, A.K., Wang, Y. and Alvarado, J.L. (2019), "Facilitating industrial symbiosis to achieve circular economy using value-added by design: A case study in transforming the automobile industry sheet metal waste-flow into Voronoi facade systems", Journal of Cleaner Production, Elsevier Ltd, Vol. 234, pp. 1033-1044.

Bendikiene, R., Ciuplys, A. and Kavaliauskiene, L. (2019), "Circular economy practice: From industrial metal waste to production of high wear resistant coatings", Journal of Cleaner Production, Elsevier Ltd, Vol. 229, pp. 1225-1232.

Bridgens, B., Powell, M., Farmer, G., Walsh, C., Reed, E., Royapoor, M., Gosling, P., et al. (2018), "Creative upcycling: Reconnecting people, materials and place through making”, Journal of Cleaner Production, Elsevier Ltd, Vol. 189, pp. 145-154.

Chouinard, U., Pigosso, D.C.A., McAloone, T.C., Baron, L. and Achiche, S. (2019), "Potential of circular economy implementation in the mechatronics industry: An exploratory research", Journal of Cleaner Production, Vol. 239, available at: https://doi.org/10.1016/j.jclepro.2019.118014.

EMF. (2015), “Towards a Circular Economy: Business Rationale for an Accelerated Transition”, Ellen MacArthur Foundation (EMF), p. 20.

Geissdoerfer, M., Savaget, P., Bocken, N.M.P. and Hultink, E.J. (2017), “The Circular Economy - A new sustainability paradigm?", Journal of Cleaner Production, Elsevier Ltd, Vol. 143, pp. 757-768.

Jawahir, I.S. and Bradley, R. (2016), "Technological Elements of Circular Economy and the Principles of 6RBased Closed-loop Material Flow in Sustainable Manufacturing”, Procedia CIRP, Elsevier B.V., Vol. 40, pp. 103-108.

Kutz, M. (Ed.). (2007), Environmentally Conscious Mechanical Design, John Wiley \& Sons, Inc., Hoboken, NJ, USA, available at: https://doi.org/10.1002/9780470168202.

De los Rios, I.C. and Charnley, F.J.S. (2017), "Skills and capabilities for a sustainable and circular economy: The changing role of design", Journal of Cleaner Production, Elsevier Ltd, Vol. 160, pp. 109-122.

Mihelcic, J.R., Crittenden, J.C., Small, M.J., Shonnard, D.R., Hokanson, D.R., Zhang, Q., Chen, H., et al. (2003), "Sustainability Science and Engineering: The Emergence of a New Metadiscipline”, Environmental Science \& Technology, Vol. 37 No. 23, pp. 5314-5324.

Nilakantan, G. and Nutt, S. (2015), "Reuse and upcycling of aerospace prepreg scrap and waste", Reinforced Plastics, Elsevier Ltd., Vol. 59 No. 1, pp. 44-51. 
Pigosso, D. and McAloone, T. (2017), "How can design science contribute to a circular economy?", Proceedings of the International Conference on Engineering Design, ICED, Vol. 5 No. DS87-5, pp. 299-307.

Ramani, K., Ramanujan, D., Bernstein, W.Z., Zhao, F., Sutherland, J., Handwerker, C., Choi, J.K., et al. (2010), "Integrated sustainable life cycle design: A Review", Journal of Mechanical Design, Transactions of the ASME, Vol. 132 No. 9, pp. 0910041-09100415.

Reh, L. (2013), "Process engineering in circular economy", Particuology, Chinese Society of Particuology, Vol. 11 No. 2, pp. 119-133.

Sauerwein, M., Doubrovski, E., Balkenende, R. and Bakker, C. (2019), "Exploring the potential of additive manufacturing for product design in a circular economy", Journal of Cleaner Production, Elsevier Ltd, Vol. 226, pp. 1138-1149.

Tolio, T., Bernard, A., Colledani, M., Kara, S., Seliger, G., Duflou, J., Battaia, O., et al. (2017), "Design, management and control of demanufacturing and remanufacturing systems", CIRP Annals - Manufacturing Technology, Vol. 66 No. 2, pp. 585-609.

Wang, P., Li, W. and Kara, S. (2018), "Dynamic life cycle quantification of metallic elements and their circularity, efficiency, and leakages", Journal of Cleaner Production, Elsevier Ltd, Vol. 174, pp. 1492-1502. 